
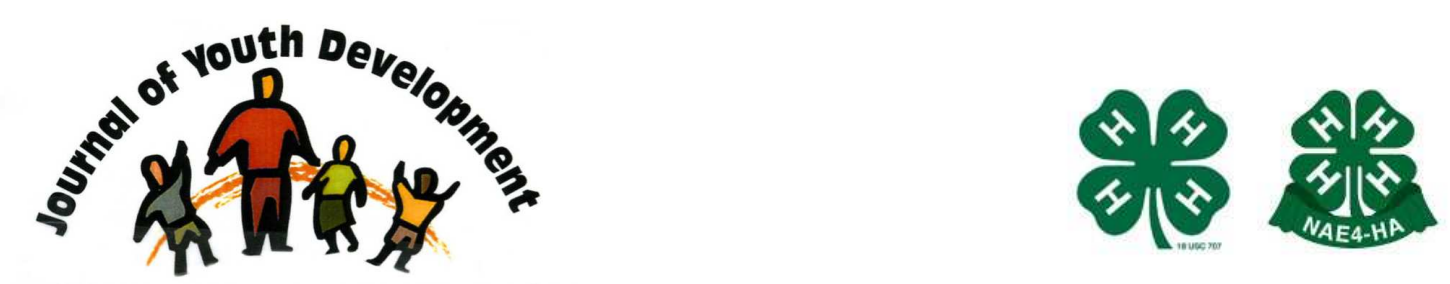

Bridging Research \& Practice

\title{
Jump-Starting Youth Community Leadership: An Evaluation of a Leadership Development Program for Lesbian, Gay, Bisexual, Transgender \& Ally Youth
}

Elizabeth M. Diaz

Gay, Lesbian \& Straight Education Network (GLSEN)

New York, NY

Joseph G. Kosciw

GLSEN

New York, NY

jkosciw@glsen.org 


\title{
JOURNAL OF YOUTH DEVELOPMENT \\ bridging research and practice



Volume 7, Number 1, Spring 2011

Article 120701PA002

\section{Jump-Starting Youth Community Leadership: An Evaluation of a Leadership Development Program for Lesbian, Gay, Bisexual, Transgender \& Ally Youth}

\author{
Elizabeth M. Diaz and Joseph G. Kosciw \\ Gay, Lesbian \& Straight Education Network (GLSEN)
}

\begin{abstract}
The GLSEN Jump-Start National Student Leadership Team, a leadership development program for lesbian, gay, bisexual, transgender (LGBT), and ally youth designed to promote direct action community organizing and community engagement. This article examines the benefits of the program for youth's socio-political development. Data came from a multi-year evaluation that examined changes over time (baseline, immediately post-program, and one-year follow-up) in community engagement between a program group $(n=103)$ and a comparison group of youth $(n=47)$. Results indicate that the program may support LGBT and ally youth's socio-political development and have positive implications for their development as community leaders, but these benefits may not be sustained after program completion. Implications for further research and program development for LGBT youth are explored.
\end{abstract}

\section{Introduction}

Much of the existing research about lesbian, gay, bisexual, and transgender (LGBT) youth populations focuses on their status as at-risk for negative outcomes. For example, research has shown that LGBT youth often experience hostile school communities where they are marginalized, bullied, harassed, and excluded and face discriminatory policies and practices (Kosciw, Greytak, Diaz \& Bartkiewicz, 2010; Sausa, 2005). Further, research has shown that such hostile experiences may place LGBT youth at heightened risk for negative outcomes, such as anxiety and depression (Almeida, Johnson, Corliss, Molnar \& Azrael, 2009; Birkett, Espelage \& Koenig, 2009; Bontempo \& D’Augelli, 2002; Goodenow, Szalacha \& Westheimer, 2006; Safren \& Heimberg, 1999).

Although it is a reality that many LGBT youth have difficult experiences in their schools and communities, a number of these youth are also thriving and are actively engaged in their 
schools and communities. However, less is known about LGBT youth in the context of healthy youth development, including positive peer relations and school and community participation. Relatively little research has examined leadership development, civic engagement, and participation in youth development programs among LGBT youth populations.

Youth development programs that encourage critical thinking about one's individual and group position in the society, analysis of power and privilege, and engagement in collective organizing can support youth's socio-political development (Ginwright \& James, 2002), a process through which "a person's knowledge, analytical skills, emotional faculties, and capacity for action in political and social systems" grow (Watts, Williams \& Jagers, 2003, p. 185). One aspect of socio-political development is socio-political control-a sense of agency and self-efficacy regarding making social and political change. Research has shown that for youth who are members of marginalized communities, promoting their sense of socio-political control may help ameliorate negative outcomes associated with experiences of bias, prejudice, and discrimination (Peterson, Lowe, Hughey, Reid, Zimmerman \& Speer, 2006; Zimmerman \& Zahniser, 1991). Programs that focus on youth's socio-political development may promote greater community engagement and healthier socio-emotional development. Indeed, research on LGBT and ally youth activism through Gay-Straight Alliances (student-led, school extracurricular clubs that often work to challenge biased and discriminatory behaviors and policies) has shown that club engagement may help youth to become more empowered and civically engaged (Russell, 2002).

Even though youth in marginalized communities may especially benefit from opportunities that promote leadership and socio-political development, they may often lack access to such opportunities (Watts \& Flanagan, 2007). LGBT youth, in particular, may face barriers to leadership and engagement within their schools and broader communities. Russell (2002) asserts that institutionalized homophobia and heterosexism create barriers to pathways to citizenship development and civic engagement for LGBT youth. Youth who do not identify as LGBT but have LGBT friends or who are involved with efforts to combat anti-LGBT bias and harassment in their communities (often referred to as "allies") may also face hostility and be stigmatized (Sweat, 2004) because of their support of LGBT people and activism. This may potentially obstruct their access to opportunities for development and civic engagement as well.

In order to provide LGBT students with leadership opportunities and to support their sociopolitical development, GLSEN (the Gay, Lesbian, and Straight Education Network) developed the Jump-Start National Student Leadership Team, a program designed to provide LGBT and ally youth with training and leadership opportunities in organizing for safer schools. In this article, we present findings from a multi-year evaluation of the program. We first discuss program theory and implementation and follow with an examination of the impact of the program on youth's leadership development and engagement with their communities through organizing and activism.

\section{GLSEN's Jump-Start National Student Leadership Team}

\section{Program Purpose, Goals, and Theory}

Founded in 1990, GLSEN is a national non-profit focused on addressing anti-LGBT bias and other issues of sexual orientation and gender identity/expression in $\mathrm{K}-12$ education in the United States. In order to support youth leadership and community organizing to make school communities safe and welcoming for all students, in 2002 GLSEN began the Jump-Start National Student Leadership Team (hereinafter, Jump-Start Team). The program is open to both LGBT youth and ally youth. 
As originally conceived, the Jump-Start Team was a 12-month program, running from July to June. The program's primary purpose was to support LGBT and ally youth's leadership and socio-political development, including building collective organizing skills and encouraging critical examination of how anti-LGBT and other bias may affect members of school communities. Additionally, the program was intended to increase their direct action organizing to improve school climates.

GLSEN's program and evaluation team developed a model for the underlying program theory. As shown in Figure 1, Jump-Start participation would directly increase youth's knowledge about the prevalence and impact of bias and harassment on school communities, grow their leadership and community organizing skills, and increase their frequency of engaging in community organizing and activism, thereby promoting youth's socio-political development.

Figure 1

Program Theory

\begin{tabular}{|c|}
\hline $\begin{array}{c}\text { Jump-Start } \\
\text { National Student } \\
\text { Leadership Team }\end{array} \backslash \sqrt{\bullet} \begin{array}{l}\text { Increased Knowledge } \\
\text { Increased Leadership and } \\
\text { Community Organizing Skills }\end{array}$ \\
$\square$
\end{tabular}

\section{Program Implementation}

The Jump-Start Team was for secondary school youth who were at least 13 years of age and expressed a desire to work on addressing anti-LGBT bias and harassment in their schools. Youth learned about the program through GLSEN's network and via youth advocacy organizations. Each program year 50 to 70 students were selected for the team. In selecting team members, program staff strived to create a team that was diverse regarding racial, ethnic, and gender identity, sexual orientation, and geographic location. Given that travel was involved, youth obtained parental permission to participate. GLSEN covered all expenses, such as travel costs.

Team members attended three multiple-day group gatherings throughout the program year, one at the beginning of the program, one 6 months into the program, and one 9 months into the program. At these gatherings, team members participated in trainings designed to provide them with information, resources, and skills to help them be effective community organizers. Trainings focused on topics such as understanding inequality and interconnected forms of oppression, navigating school systems, responding to critics, organizing and facilitating workshops, and planning actions and campaigns. As part of these trainings, team members practiced utilizing the information, resources, and skills. Program participants were actively involved in organizing to address these issues in their communities, focusing on the following areas:

1) supporting Gay-Straight Alliances,

2) organizing local activities to commemorate national advocacy events (e.g., the National Day of Silence),

3) organizing campaigns directed at changing discriminatory or exclusionary school policies, and

4) training school staff on school climate issues related to sexual orientation and gender identity/expression. 
Throughout the year team members received on-going support from GLSEN staff through semimonthly group and individual telephone calls. Additionally, team members could communicate via email and telephone with staff and other team members at anytime throughout the program. Team members contributed 10 to 15 hours of service per month focused on leading collective efforts in their local communities. Program staff supported members in developing goals and activities, but youth ultimately decided how they would engage in organizing in their communities. At the end of the program, youth created a portfolio highlighting their accomplishments and skills. The core components of the program have remained the same throughout its history. However, since 2009, the Jump-Start Team is implemented at the local level by GLSEN affiliates- program staff from the national office work with local GLSEN leaders to conduct trainings and provide support to youth.

\section{Method}

In this evaluation we sought to answer the following questions:

1. What leadership and organizing skills did Jump-Start members learn through program participation?

2. Does Jump-Start participation affect youth's engagement with community organizing and activism?

\section{Study Design}

The evaluation design was quasi-experimental, utilizing pre- and post-surveys to examine changes over time between a Jump-Start program group and a comparison group of youth. To obtain comparison group participants, GLSEN distributed electronic announcements about the study through its networks and via listservs and websites of youth advocacy organizations. In addition, youth who applied to but were not selected for the Jump-Start Team were invited to participate in the comparison group. Youth in the comparison group were all middle and high school students, at least 13 years of age who were involved in organizing for safer schools in their communities. All study participants were required to obtain parental consent prior to taking part in the study and study participation was voluntary for both groups.

Data for this evaluation were collected through questionnaires administered to program and comparison groups from three time points: prior to the start of the program (baseline or Time 1 ), immediately at the end of the program year (Time 2), and one year after the end of the program Time 3). In each questionnaire, we examined skills that youth had learned through the Jump-Start Team and frequencies of participation in a variety of community organizing activities. To assess what leadership and organizing skills youth learned, we utilized responses to an open-ended item at Time 2 asking respondents to describe the types of skills they had learned as part of the team.

To examine possible effects of program participation on community engagement, we tested significant differences over time in the program and comparison groups' frequency of involvement in organizing in their communities. Engagement in community organizing/activism was assessed with a 16-item, modified version of the Index of Civic and Political Engagement (Andolina, Keeter, Zukin \& Jenkins, 2003) that asked respondents how often in the past 12 months they had participated in activities such as working collaboratively to address community problems or contacting a public official to share an opinion. 


\section{Sample}

The sample for this evaluation consisted of 103 Jump-Start members who participated in the program during the 2004-05 and 2005-06 school years and 47 youth in the comparison group. (Ten team members did not complete the program and were excluded from the analysis, along with two individuals who were originally part of the comparison group but then became part of the Jump-Start team the following year while the evaluation was still underway). The JumpStart group and comparison group were relatively similar in terms of their individual characteristics (see Table 1). About a fifth in each group identified as heterosexual and a majority identified as lesbian, gay or bisexual, female, and White. The two groups differed somewhat with regard to gender with Jump-Start participants being more likely to identify as male ( $45.6 \%$ vs. $27.7 \% ; \chi^{2}=6.88, d f=3, p<.10$, Cramer's $\mathrm{V}=.21$ ). There were fewer White youth in the Jump-Start group, although the differences between individual racial/ethnic categories were not statistically significant $\left(\chi^{2}=8.23, d f=5, p>.10\right.$, Cramer's V =.23). The groups were not statistically different regarding sexual orientation; a majority of both groups were lesbian, gay, or bisexual $\left(\chi^{2}=.04, d f=2, p>.10\right.$, Cramer's $\left.\mathrm{V}=.02\right)$. The average age at baseline for both groups was approximately 16 years.

Table 1

Individual Characteristics as a Percentage of the Sample $(\mathrm{N}=150)$

\begin{tabular}{|l|c|c|}
\hline Characteristic & $\begin{array}{c}\text { Jump-Start } \\
\text { Group } \\
(n=103)\end{array}$ & $\begin{array}{c}\text { Comparison } \\
\text { Group } \\
(n=47)\end{array}$ \\
\hline Sexual Orientation & & 70.2 \\
\hline Lesbian, Gay, or Bisexual & 68.9 & 19.1 \\
\hline Heterosexual & 19.4 & 10.6 \\
\hline Other orientation (e.g., queer) & 11.7 & \\
\hline Gender & & 61.7 \\
\hline Female & 51.5 & 27.7 \\
\hline Male & 45.6 & 6.4 \\
\hline Transgender & 1.9 & 4.3 \\
\hline Other gender (e.g., androgynous) & 1.0 & 78.7 \\
\hline Race/Ethnicity & & - \\
\hline White & 61.2 & 8.5 \\
\hline Black or African American & 3.9 & 4.3 \\
\hline Hispanic or Latino/a, any race & 24.3 & - \\
\hline Asian or Pacific Islander & 2.9 & 8.5 \\
\hline American Indian or Alaska Native & 1.0 & \\
\hline Multiracial & 6.8 & \\
\hline
\end{tabular}

\section{Results}

\section{Self-Reported Skills Obtained Through Jump-Start Team Participation}

In response to an open-ended survey question at the end of the program year, Jump-Start Team members reported gaining a wide range of skills and knowledge through their participation in the program ( $n=59$; see Table 2$)$. The skills that were most commonly mentioned by youth were those related to:

1) planning and delivering workshops and other events, 
2) working with other people and group leadership,

3) communication skills, including interpersonal communication and public speaking, and

4) information and resources for organizing for safer schools.

Table 2

Self-Report of Skills Obtained Through Jump-Start Team Participation $(n=59)$

\begin{tabular}{|l|c|c|}
\hline Skill & \% & n \\
\hline Workshop/event planning and delivery & 62.7 & 37 \\
\hline Working collaboratively and team leadership & 49.2 & 29 \\
\hline Communication skills & 39.0 & 23 \\
\hline Information and resources & 28.8 & 17 \\
\hline Personal growth & 27.1 & 16 \\
\hline Networking, outreach, and coalitions & 18.6 & 11 \\
\hline Community organizing skills, non-specific & 16.9 & 10 \\
\hline General organizational skills (e.g., time management) & 16.9 & 10 \\
\hline Supporting Gay-Straight Alliances & 11.9 & 7 \\
\hline Logistics of campaign and action planning & 8.5 & 5 \\
\hline Other (e.g., fundraising, lobbying) & 22.0 & 13 \\
\hline
\end{tabular}

In addition to specific skills, team members also mentioned areas of personal growth that they attributed to their participation in the program, such as greater self-efficacy with regard to making a positive impact in their communities. (Note about language: In discussing youth's responses regarding skills, we use third-person pronouns [they, their] rather than first-person pronouns [he/his, she/her]. Not all of the youth in the sample use male or female pronouns and for the sake of consistency we choose to use third-person pronouns.)

Event planning and delivery. Almost two-thirds (62.7\%) of respondents mentioned skills related to planning and delivering various types of events, such as facilitating a workshop or organizing a "summit" or gathering of other student leaders in their community. For example, one student described learning "how to plan and host a youth summit (logistics, agenda, presenters, etc.)." Another student said that they had learned "how to facilitate a workshop in a semi-professional setting" as well as how to successfully plan school- and community-wide events.

Working collaboratively and team leadership. Almost half (49.2\%) described skills such as learning to work more effectively in partnerships, to build coalitions and network with other community members, and successfully lead a group of people toward a common goal. For example, one student said: "I've learned how to better negotiate and work with the adult members of my community. Also, I learned a lot about delegating tasks and responsibilities to other members of my group when we have a big event that we are planning." Another student said that they had "learned about teamwork and delegating and why [it is] so important." 
Several students mentioned learning how to work with large groups of people toward a common goal.

Communication skills. At the end of the program year, 39.0\% described learning a variety of communication skills. Several respondents spoke specifically about developing more effective interpersonal communication skills as a result of their involvement with the Jump-Start Team. For example, one student said: "I have learned to be a much more effective communicator and to use that in my organizing when things get rough between members of a given organizing group." Another student commented that they had learned "[talk] with people who are from different backgrounds (including age, sex, gender, class, ethnicity)."

One student reported that their experiences as a Jump-Start Team member positively affected their public speaking skills:

I have learned so much throughout this past year. I cannot even explain the difference this team has made on me. Between using the workshops and resources I learned from GLSEN at my school and other schools I have become more confident in public speaking and more confident in talking about LGBT issues.

Several students commented on learning strategies for communicating with the media, such as how to handle interviews. For example, one student said: "I gained knowledgeable skills in dealing with the media in a courteous manner, sending press releases that guarantee media coverage, and how to deal with impromptu interviews."

Information and Resources. About a quarter (28.8\%) of respondents mentioned learning specific information or resources that they believed had contributed to their growth as community organizers. For example, respondents described learning about diverse communities, the experiences of transgender students, and students' legal rights. In addition, respondents commented about useful GLSEN resources they received while on the team (e.g., GLSEN Jump-Start Guides).

One student said that all of the resources they had received strengthened the various skills they acquired while on the team and were useful in a variety of community organizing activities: "I used them to run my summit...and some skills for the national workshop I did for my conference with the church." Furthermore, two respondents specifically mentioned learning strategic approaches to organizing. One student commented that they had "learn[ed] how to use certain tactics to put pressure on decision-makers in order to achieve [their] goal," and another person discussed learning how to the navigate school administration, specifically knowing "the order of people to talk to in order to get something changed at [their] school."

Personal Growth. More than a quarter (27.1\%) of respondents described how the JumpStart Team was a personal growth experience for them. These respondents tended to describe areas of personal growth, such as becoming more "open-minded" and increased self-confidence and self-efficacy in effecting community change, that were presumably related to other skills gained while on the team. For example, a student said that their involvement with the JumpStart Team had taught them "how to be strong and believe in myself. Find something that I am very passionate about. Find a place that I finally felt I belonged." Two students described how the team contributed to growth in their self-efficacy in affecting community change. One said that they had "learned how to stand up and speak out against injustice... learned that youth really can make a difference," and a second student shared the following: 
When I first came to the Jump-Start team, I was an awkward teenager who knew nothing about LGBT issues. Having been oppressed for years, I knew that I wanted to make a difference, and when I joined the JSLT, I learned all the skills to do anything and everything about LGBT issues.

In addition to the above, Jump-Start Team members mentioned a variety of other types of skills that they had acquired while in the program. These ranged from general organizational skills, such as better time management, to skills specific to community organizing, such as building coalitions and the logistics of planning an action campaign (see Table 2). It is somewhat surprising that relatively few youth specifically mentioned learning skills related to supporting Gay-Straight Alliances (GSAs), given that doing so was supposed to be a key program activity. It is possible that respondents who did not specifically mention GSAs also utilized their skills and knowledge to support student clubs in their communities. But, we cannot know from this data to what extent this may be true.

\section{Effect of Jump-Start Team Participation on Community Engagement}

In addition to growing youth's skills, based on the program theory we expected program participation to increase youth's community engagement. We examined whether there were significant differences over time in the program and comparison groups' frequency of involvement with various indicators of community organizing and civic engagement. We expected that there would be an increase over time among Jump-Start Team members, but not among youth in the comparison group. To test this hypothesis, a mixed between-within subject repeated measures analysis of variance test was conducted and the interaction effect for Group $x$ Time examined, controlling for gender and race/ethnicity because of the differences between the two groups. Cases were deleted list-wise, thus, only respondents with data at all three time-points were included in the analyses.

We found that participation in the Jump-Start Team was related to a significant increase in community engagement. Among program participants, frequency of involvement with community organizing activities increased from Time 1 (pre-program) to Time 2 (immediately at the end of the program year; see Table 3). In contrast, engagement in community organizing did not significantly change over time for the comparison group. However, although there were changes in Jump-Start Team participants' from pre- to immediately post-program, this change was not maintained one year after the program: at Time 3, Jump-Start Team participants' community organizing activity decreased to Time 1 levels $(n=79$, Wilks' Lambda $=.90, \Re(2$, $69)=3.96, p<.05$, partial eta squared $=.10$; see also Table 3 ). These results suggest that the program itself provided youth with opportunities and incentive for community engagement, opportunities and incentive which youth in the comparison group may not have had and which team members may no longer have had after they graduated from the program. 
Table 3

Changes Over Time in Community Organizing Activities:

Jump-Start Team Participants vs. Comparison Group N=79

\begin{tabular}{|l|l|l|l|l|l|}
\hline \multicolumn{3}{|c|}{ Jump-Start Team Participants N=52 } & \multicolumn{3}{c|}{ Comparison Group N=27 } \\
\hline \multicolumn{3}{|c|}{ Mean (Standard Error) } & \multicolumn{3}{c|}{ Mean (Standard Error) } \\
\hline Time 1 & Time 2 & Time 3 & Time 1 & Time 2 & $\begin{array}{l}\text { Time 3 } \\
\text { Conclusion }\end{array}$ \\
\hline Pre-Program & $\begin{array}{l}\text { End-of- } \\
\text { Program }\end{array}$ & $\begin{array}{l}\text { One Year } \\
\text { Post }\end{array}$ & Pre-Program & $\begin{array}{l}\text { End-of- } \\
\text { Program }\end{array}$ & $\begin{array}{l}\text { One Year } \\
\text { Post }\end{array}$ \\
\hline $2.32(.05)^{2}$ & $2.50(.05)^{1,3}$ & $2.34(.05)^{2}$ & $2.21(.07)$ & $2.20(.07)$ & $2.24(.07)$ \\
\hline $\begin{array}{l}\text { Note. Statistically significant differences between time points are indicated by superscript } \\
\text { numbers - e.g., superscript "2" for the program group's Time 1 score indicates that it is } \\
\text { statistically different from the Time 2 score. }\end{array}$
\end{tabular}

\section{Conclusion and Implications}

There are several limitations to this study that warrant mention. First, findings from this evaluation cannot be generalized to all development programs for LGBT and ally youth. Second, given the sample size, we were not able to examine potential group differences among team members. Jump-Start Team members were quite diverse in terms of their school environments, sexual orientation, and racial/ethnic identity, but in this study we were not able to examine how community context and various aspects of youth's identity may have impacted their experiences while on the team or their community engagement (e.g., the experiences of ally youth vs. those who were LGBT-identified). The sample size also limited our ability to examine both youth who did not complete the program and attrition from the study. Third, we had only self-reports of youth's community engagement and independent reports about team members' organizing efforts (e.g., the perspectives of program staff) may have added to our understanding of how the program impacts LGBT and ally youth's community engagement. Finally, we do not know the extent to which youth-both those in Jump-Start and those in the comparison group-may have been involved with other youth development programs or activities.

Findings from this evaluation of GLSEN's Jump-Start National Student Leadership program are promising and demonstrate that many participants gained skills and knowledge that they believed helped them to become strong community leaders. Most of the skills described by participants map back to the trainings they received during the program, such as organizing and facilitating meetings and working collaboratively with other community members, and may prove useful to youth in their continued community organizing work as well as in other facets of their lives. Experiences while on the team also contributed to personal growth for some youth in areas such as self-confidence and self-efficacy. Results also suggest that this program increases LGBT and ally youth's community engagement, and thus, supports their socio-political development. In that the increase in community organizing activity during the program was not sustained a year later suggests that it may be the program itself that provided youth with 
opportunities for community engagement, opportunities that they may not have had after program completion and that comparison group youth did not have. Given that team members were expected to engage in 10 to 15 hours per month in organizing in their local communities, it could also be that youth had more incentive to engage in such activities during the program, compared to after the program and compared to youth in the comparison group. Additionally, a year after the program, many former team members were out of high school and in college and/or employed-these life changes may have changed the nature of their community engagement. Nevertheless, participating in GLSEN's Jump-Start program may help to support LGBT and ally youth's socio-political development and may have positive implications for their development as community leaders. As we continue to examine data from the evaluation, it will be important to explore how changes in community engagement while in the program relate to positive outcomes in participants' socio-emotional well-being over-time.

Programs that support youth leadership and community engagement, such as Jump-Start, may be important for the healthy development of LGBT and ally youth. By supporting their sociopolitical development, such programs may, in turn, promote greater well-being and mitigate the harmful effects of too often negative experiences. For some LGBT youth, it may also provide an opportunity where they can be open about their sexual orientation and/or gender identity while being engaged in their communities as leaders. Youth service providers, including those providing youth development programs, should consider the ways in which supporting LGBT and ally youth's socio-political development may ultimately contribute to their socio-emotional well-being. With regard to LGBT youth specifically, youth development program providers need to 1 ) be cognizant of the presence of LGBT participants (who may or may not be open about their sexual orientation or gender identity) in their programs, and 2) consider the differential effects of program participation, which may not be benefitting all youth in similar ways. Failing to do so may further marginalize some youth, including LGBT and ally youth.

We have just begun to understand LGBT youth's experiences in youth development programs more broadly. More research is needed that examines LGBT youth's socio-political and leadership development, including potential benefits for health and well-being, as well as more evaluations of the potential impact of participation in various types of youth development programs.

\section{References}

Almeida, J., Johnson, R., Corliss, H., Molnar, B., \& Azrael, D. (2009). Emotional distress among LGBT youth: The influence of perceived discrimination based on sexual orientation. Journal of Youth and Adolescence, 38, 1001-1014.

Andolina, M., Keeter, S., Zukin, C., \& Jenkins, K. (2003). A Guide to the Index of Civic and Political Engagement. Center for Information and Research on Civic Learning and Engagement (CIRCLE). Medford, MA: Jonathan M. Tisch College of Citizenship and Public Service, Tufts University.

Birkett, M., Espelage, D., \& Koenig, B. (2009). LGB and questioning students in schools: The moderating effects of homophobic bullying and school climate on negative outcomes. Journal of Youth and Adolescence, 38(7), 989-1000. 
Bontempo, D., \& D'Augelli, A. (2002). Effects of At-School Victimization and Sexual Orientation on Lesbian, Gay, or Bisexual Youths' Health Risk Behavior. Journal of Adolescent Health, 30, 364-374.

Ginwright, S., \& James, T. (2002) From assets to agents of change: Social justice, organizing, and youth development. New Directions for Youth Development, 96, 27-46.

Goodenow, C., Szalacha, L., \& Westheimer, K. (2006). School support groups, other school factors, and the safety of sexual minority adolescents. Psychology in the Schools, 43(5), 573589.

Kosciw, J., Greytak, E., Diaz, E., \& Bartkiewicz, M. (2010). The 2009 National School Climate Survey: The Experiences of Lesbian, Gay, Bisexual, and Transgender Youth in Our Nation's School. New York: GLSEN.

Peterson, N., Lowe, J., Hughey, J., Reid, R., Zimmerman, M., \& Speer, P. (2006). Measuring the intrapersonal component of psychological empowerment: Confirmatory factor analysis of the sociopolitical control scale. American Journal of Community Psychology, 38, 287-297.

Russell, S.T. (2002). Queer in America: Citizenship for sexual minority youth. Applied Developmental Science, 6(4), 258-263.

Safren, S., \& Heimberg, R. (1999). Depression, hopelessness, suicidality, and related factors in sexual minority and heterosexual adolescents. Journal of Consulting and Clinical Psychology, 6Л6), 859-866.

Sausa, L. (2005). Translating research into practice: Trans youth recommendations for improving school systems. Journal of Gay \& Lesbian Issues in Education, 3(1), 15-28.

Sweat, J.W. (2004). Crossing boundaries: Identity and activism in Gay-Straight Alliances (Doctoral dissertation). Retrieved from Dissertations \& Theses: Full Text (UMI No. 3148503).

Watts, R., \& Flanagan, C. (2007). Pushing the envelope on youth civic engagement: A developmental and liberation psychology perspective. Journal of Community Psychology, 35(6), 779-792.

Watts, R., Williams, N., \& Jagers, R. (2003). Sociopolitical development. American Journal of Community Psychology, 31(1/2), 185-194.

Zimmerman, M., \& Zahniser, J. (1991). Refinements of sphere-specific measures of perceived control: Development of a sociopolitical control scale. Journal of Community Psychology, 19(2), 189-204.

(C) Copyright of Journal of Youth Development $\sim$ Bridging Research and Practice. Content may not be copied or emailed to multiple sites or posted to a listserv without copyright holder's express written permission. However, users may print, download or email articles for individual use. 